\title{
Evaluation of Indoor Penetration Loss and Floor Loss for a DVB-H Signal at $514 \mathrm{MHz}$
}

\author{
David Plets, Wout Joseph, Leen Verloock, Emmeric Tanghe, Luc Martens \\ Department of Information Technology, Ghent University/IBBT, Gaston Crommenlaan 8, B-9050 Ghent, Belgium \\ Email: david.plets@intec.ugent.be
}

\begin{abstract}
In this paper, indoor penetration loss and floor loss for a DVB-H signal at $514 \mathrm{MHz}$ retransmitted by a gap filler are investigated. Measurements in $\mathbf{1 4}$ different houses (detached houses, semidetached houses, terraced houses and apartments) and $\mathbf{1 2 1}$ rooms have been performed for three different radiated power levels. Rooms have been categorized according to their location with respect to the gap filler (same room, adjacent rooms, non-adjacent rooms, other floors, and outdoor locations). It is shown that the distribution of the room penetration loss is lognormal. A comparison with existing models is made and a model for penetration through different floors is proposed.
\end{abstract}

\section{INTRODUCTION}

DVB-H (Digital Video Broadcasting-Handheld) systems enable broadcast access for hand-held terminals. DVB-H is based on the specifications and guidelines of ETSI [1]-[4]. Different measurement campaigns are executed to investigate the performance of an outdoor DVB-H network in relation to different system parameters (modulation, guard interval, MPE-FEC or multi protocol encapsulation - forward error correction coding rate) and reception conditions (portable, mobile, indoor, outdoor,...) [5]-[9]. The indoor reception of the DVB-H signal by outdoor base station antennas is not always satisfying. The quality of the received signal depends on different factors including the environment (rural, suburban or urban), the distance between the transmitter and the receiver, the location within the building (e.g., lower floors, cellar, etc.), and the materials of the building (e.g., metalcoated windows, walls with reinforced concrete). An option to improve the indoor coverage consists of retransmitting a copy of the DVB-H signal over an existing HFC (hybrid fiber coax) network. At the cable network subscribers' side a small gap filler is connected to the cable [10]. This small gap filler processes the received DVB-H signal and retransmits it using an indoor antenna. The small gap filler works complementary with the signal transmitted by the outdoor base station antenna which provides outdoor coverage in the concerned area.

In this paper, indoor penetration of a DVB-H signal in the UHF (Ultra High Frequency) band (selected frequency is $514 \mathrm{MHz}$ ) is investigated in residential houses and a measurement methodology is proposed. In the literature, mostly studies about outdoor-to-indoor penetration are available [11]-[16]. In e.g., [13] path loss and penetration loss is investigated at $5.85 \mathrm{GHz}$ into homes. Also studies about penetration through different types of walls and materials are available [17]-[20]. For these studies a measurement setup at two sides of a specific wall (often in a laboratory) is placed. Indoor penetration loss is investigated in the $2.4 \mathrm{GHz}$ ISM (industrial, scientific and medical) frequency band [18], [20] and around 800 $900 \mathrm{MHz}$ [20]-[22]. A model for penetration within buildings is proposed in [11], [23] and parameters at $1800 \mathrm{MHz}$ are proposed. Furthermore an indoor path loss model at $900 \mathrm{MHz}$ for office environments is developed in [22], [23].

\section{OBJectives}

The objective of this paper is to determine and model the indoor penetration losses (i.e., losses between different rooms within houses). Moreover rooms are categorized according to their location with respect to the gap filler and measurements in 14 different houses and 121 rooms have been executed for three different radiated power levels. The distribution of the room penetration loss is investigated, a comparison with existing models is made, and a model for indoor penetration through different floors is proposed. The results of this paper can be used by broadcasters and operators to determine the optimal radiated power (and thus cost) of indoor gap fillers and to perform link budget calculations for indoor coverage. The results can also be used for standardization (e.g., in [10]). The outline of this paper is as follows. The configuration, different settings of the DVB-H system, categorization, and measurement methodology are described in Section III. In Section IV, the indoor penetration loss is evaluated and modeled. Finally, the conclusions are presented in Section V.

\section{Methodology}

\section{A. Configuration}

1) Transmission configuration: We investigate the indoor coverage of small gap fillers at $514 \mathrm{MHz}$ in different houses in the city of Mechelen, Belgium. Measurements are executed in an environment without an existing outdoor DVB-H transmitting network.

The settings of the DVB-H signal are as follows: a modulation scheme of 16-QAM 1/2, MPE-FEC 7/8 and guard interval GI of $1 / 8$, corresponding with a physical bit rate of $9.68 \mathrm{Mbps}$. Table I shows the parameters and corresponding values for the transmitted DVB-H signal used for the measurements in Mechelen. The small gap filler with antenna is placed in the room where the gap filler can be connected to the cable network. The gap filler is fed with the DVB-H signal transported on the HFC-cable network with a bandwidth (BW) of $8 \mathrm{MHz}$ and a center frequency of $514 \mathrm{MHz}$. The DVB$\mathrm{H}$ signal is filtered out of the cable network, amplified, and 
finally retransmitted using an indoor loop antenna (diameter of $20 \mathrm{~cm}$, thickness of $4 \mathrm{~mm}$ ). Fig. 1 shows the configuration to transport and radiate the DVB-H signal with a small gap filler. An ASI (Asynchronous serial communication) stream is modulated at $514 \mathrm{MHz}$ (R\&S modulator). The DVB-H signal arrives in the subscribers' houses over the existing HFC-cable network. The small gap filler processes the received DVB-H signal and retransmits it at an adjustable power level.

\begin{tabular}{|c|c|}
\hline Parameter & Value \\
\hline Frequency & $514 \mathrm{MHz}$ \\
FFT mode & $4 \mathrm{~K}$ \\
Modulation scheme & $16-\mathrm{QAM}$ \\
Inner code rate & $1 / 2$ \\
Guard interval GI & $1 / 8$ \\
MPE-FEC & $7 / 8$ \\
Channel bandwidth BW & $8 \mathrm{MHz}$ \\
Number of rows & 768 \\
PID (packet identifier) & 4145 \\
ERP (Effective Radiated Power) & $0 / 9 / 19 \mathrm{dBm}$ \\
\hline
\end{tabular}

\section{TABLE I}

PARAMETERS OF THE DVB-H SIGNAL USED FOR THE TRIAL IN MECHELEN.

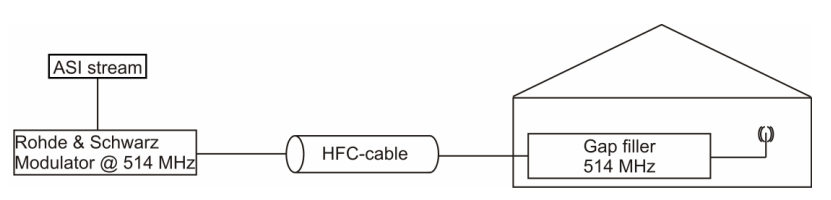

Fig. 1. Setup for transmission of DVB-H signal into houses in Mechelen.

2) Power levels: The measurements are repeated for three different output power levels of the gap filler. These ERPlevels (Effective Radiated Power) are: $0 \mathrm{dBm}, 9 \mathrm{dBm}$ and $19 \mathrm{dBm}$ (EIRP or Equivalent Isotropic Radiated Power levels of $2.15,11.15$ and $21.15 \mathrm{dBm}$ ). In this paper we use ERP (instead of EIRP) as broadcasters use mostly this quantity in practice. The power available on the HFC-cable where the connection with the gap filler is made (at the subscribers' house) varies dependent on the distance to the amplifier on the cable network. By proper channel filtering and amplification the three ERP levels are obtained.

3) Selection of the houses for the measurements: In Belgium (and Europe) the typical types of residential houses are detached houses, semidetached houses, terraced houses, and apartments. The measurements are performed in fourteen residential houses, in Mechelen: 3 apartments, 4 detached houses, 2 semidetached, and 5 terraced houses are selected for the measurement campaign. The selection thus consists of $23 \%$ detached houses, $15 \%$ semidetached houses, $39 \%$ terraced houses, and $23 \%$ apartments.

4) Categorization: The 121 different rooms of the 14 investigated houses can be categorized. We define the following categories: same room (room where small gap filler is installed), adjacent rooms (rooms adjacent to the room where the small gap filler is installed), non-adjacent rooms (rooms situated more than one room away from the room with the small gap filler), other floors (rooms on different floors), and outdoor locations (around the house, terrace, garden, etc.). Fig. 2 shows a ground plan of a residential house and the considered categories depending on the location of the small gap filler. Based on these categories and the results of this paper, broadcasters and operators will be able to determine for which ERP level good reception can be obtained for a certain category.

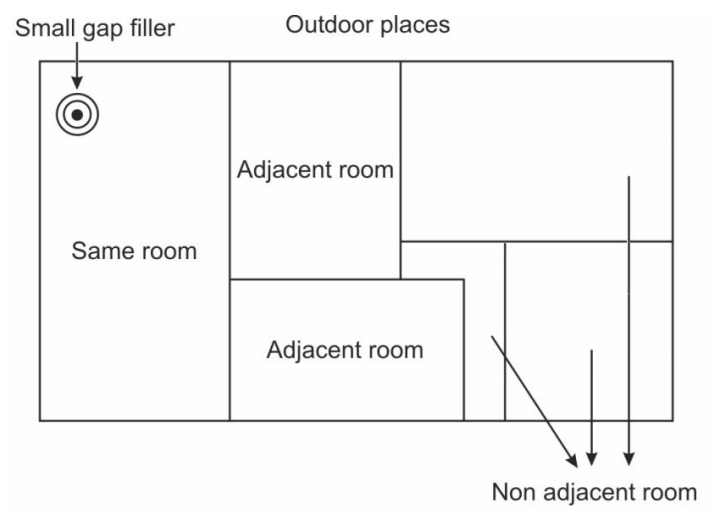

Fig. 2. Ground plan of a residential house with the different categories of rooms and the location of the small gap filler.

\section{B. Measurement procedure and equipment}

The measurements are performed with a DVB-H tool implemented on a PCMCIA card with a small receiver antenna [6][8]. The gain of the antenna is $-5 \mathrm{dBi}$. The PCMCIA card is plugged into a laptop, which is used to collect and process the measurements later. Every $0.5 \mathrm{~s}$, a sample is recorded, while the receiver is either locked or unlocked [6]-[8]. A locked receiver can receive DVB-H frames, which are either correct or incorrect. Incorrect tables can be corrected by the MPEFEC code. The tool also logs parameters such as CINR and electric-field strength.

The gap filler and the transmitting antenna are positioned in the room where the gap filler could be connected to the HFC-cable, generally in the living room. The height of the transmitting antenna is $1.8 \mathrm{~m}$ above ground level.

To investigate the penetration loss, the electric-field value (E) is monitored in the different rooms of the houses. For each room of the investigated 14 houses these parameters are recorded by walking around during a minute. Since the samples are recorded each $0.5 \mathrm{sec}$, walking around during a minute corresponds to about 120 samples. For 121 rooms and 3 ERP levels this results in a total of 43,560 samples of the electric-field strength.

\section{Room penetration loss}

The room penetration loss (RPL) is defined here as the difference between the average received electric-field level $[\mathrm{dB} \mu \mathrm{V} / \mathrm{m}]$ measured in the room where the gap filler is 
located (same room) and the average received electric-field level measured in the different other rooms (adjacent, nonadjacent, other floors, and outdoor). The room penetration loss is a combination of the path loss and the attenuation due to obstructions between the rooms. We categorize the room penetration loss in four types: room penetration loss of adjacent rooms $\left(\mathrm{RPL}_{\mathrm{adj}}\right)$, non-adjacent rooms $\left(\mathrm{RPL}_{\text {non-adj }}\right)$, rooms on other floors $\left(\mathrm{RPL}_{\mathrm{other}}\right)$, and outdoor locations (RPL $\left.\mathrm{R}_{\text {outdoor }}\right)$. These losses are determined as follows:

$$
\mathrm{RPL}_{\mathrm{x}}=\mathrm{E}_{\text {same }}[\mathrm{dB} \mu \mathrm{V} / \mathrm{m}]-\mathrm{E}_{\mathrm{x}}[\mathrm{dB} \mu \mathrm{V} / \mathrm{m}]
$$

With $\mathrm{x}=$ adj, non-adj, other, or outdoor and where $\mathrm{E}_{\text {same }}$ is the average electric-field level measured in the room with the small gap filler, $E_{a d j}$ is the average electric-field level measured in adjacent rooms, $E_{\text {non-adj }}$ in the non-adjacent rooms, $\mathrm{E}_{\text {other }}$ on the other floors, and $\mathrm{E}_{\text {outdoor }}$ is measured outdoor. These definitions are similar to those of [12], [13] where penetration loss is defined using power values (difference of fields in $\mathrm{dB} \mu \mathrm{V} / \mathrm{m}$ or powers in $\mathrm{dBm}$ results in equal penetration loss values). Also standard deviations of the room penetration losses will be discussed in Section IV-A.

\section{EVALUATION AND MODELING OF PENETRATION LOSSES}

\section{A. Penetration losses}

Fig. 3 shows the cumulative distribution function (CDF) of the room penetration loss (Prob[RPL $[\mathrm{dB}]<$ abscissa]) for the different categories and powers. All rooms are measured three times for an ERP of $0 \mathrm{dBm}, 9 \mathrm{dBm}$, and $19 \mathrm{dBm}$. Theoretically the room penetration loss (RPL) for the three output powers must have the same value in the specific category because the measurements are repeated for the three ERPs on the same locations (see also Section III-C). Practically the results of the room penetration loss can vary due to different reasons. Firstly, the environment changes a little bit during the measurements. Secondly, the places in the room where measurements are performed are not always the same. Other reflections contribute to the total measured values and can cause constructive and destructive interference. Thirdly, an average value over the concerned room is taken into account. When the room is larger, the results will vary more.

Table II summarizes the $50^{\text {th }}$ and $90^{\text {th }}$ percentiles (noted as $\mathrm{p}_{50}(\mathrm{RPL})$ or median, and $\mathrm{p}_{90}(\mathrm{RPL})$, respectively) of the room penetration loss derived from Fig. 3. Also the standard deviations $\sigma$ of the RPL are shown. The values are presented for the different categories, and for the different ERPs. Also the (linear) average value for all ERPs for each category is shown in bold in the column "All" of Table II.

For each category the room penetration losses are similar for the different ERPs (Table II). The deviation between the minimum and maximum room penetration loss for the same category varies only between $0.9 \mathrm{~dB}$ and $2 \mathrm{~dB}$. The standard deviations of the RPLs agree also well for the different ERPs in each category (right part of Table II). Standard deviations $\sigma$ of the RPL range from $4.6 \mathrm{~dB}$ (other floors) to $9.4 \mathrm{~dB}$ (outdoor

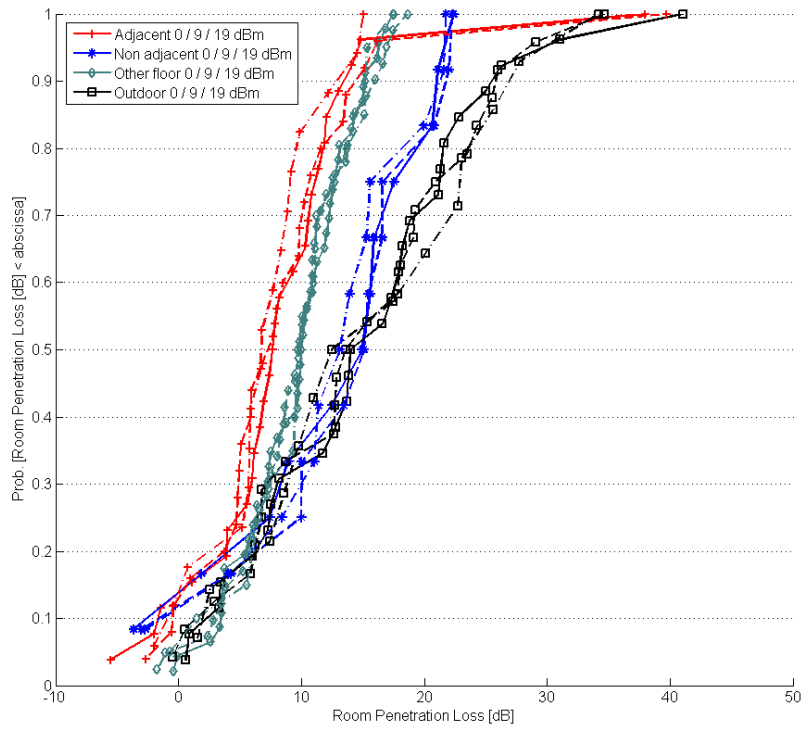

Fig. 3. Cumulative distribution function of RPL for different categories of rooms.

locations) for all data. The $50^{\text {th }}$ and $90^{\text {th }}$ percentile values for all the samples over the different categories are the lowest for the adjacent rooms $(7.7 \mathrm{~dB}$ and $14.2 \mathrm{~dB}$ respectively). The $90^{\text {th }}$ percentile of the RPL gives an idea about the highest penetration losses that can be expected for each category. The lowest values are obtained for the adjacent rooms $(14.2 \mathrm{~dB})$, followed by the other floors $(15.3 \mathrm{~dB})$ and the non-adjacent rooms $(21.7 \mathrm{~dB})$. The highest RPL values are obtained for outdoor locations $(26.2 \mathrm{~dB})$.

The values for the adjacent rooms and the other floors approach each other. The room penetration loss for the other floors is lower than the value for the non-adjacent rooms because some of the rooms classified as other rooms are located above the antenna and could be considered as adjacent rooms. The room penetration values for non-adjacent rooms are on average about $8 \mathrm{~dB}$ higher than the losses for adjacent rooms $\left(90^{\text {th }}\right.$ percentile).

To assess the lognormality of the room penetration loss, we performed a statistical goodness-of-fit test on the RPL samples. A Kolmogorov-Smirnov (K-S) test was conducted at significance level $\alpha=0.05$, wherein the empirical CDF of each investigated category of rooms was compared to a lognormal CDF with corresponding median and standard deviation from Table II (column “All”). For the measurements, this K-S test passed for all categories. The high success rate of the K-S test leads us to conclude that the RPL measurements in all categories exhibit lognormal large-scale fading statistics.

Table III lists literature about indoor penetration losses. COST231 [11] reports wall losses at $1800 \mathrm{MHz}$ of $3.4 \mathrm{~dB}$ for light walls and $6.9 \mathrm{~dB}$ for heavy walls (multi-wall model). We obtain median losses of $7.7 \mathrm{~dB}$ for adjacent rooms (corresponding with 1 wall) and $14.9 \mathrm{~dB}$ (mostly 2 walls) for non-adjacent rooms (Table II) at $514 \mathrm{MHz}$, indicating that in the considered houses in our study mostly "heavy walls" are 


\begin{tabular}{|c|c|c|c|c||c|c|c|c||c|c|c|c|}
\hline Category & \multicolumn{4}{|c|}{ median RPL [dB] } & \multicolumn{4}{c|}{ p$_{90}$ (RPL) [dB] } & \multicolumn{4}{c|}{$\sigma$ [dB] } \\
\hline ERP [dBm] & 0 & 9 & 19 & All & 0 & 9 & 19 & All & 0 & 9 & 19 & All \\
\hline Adjacent & 7.8 & 7.3 & 6.8 & $\mathbf{7 . 7}$ & 13.4 & 14.4 & 12.9 & $\mathbf{1 4 . 2}$ & 7.8 & 8.1 & 4.7 & $\mathbf{7 . 2}$ \\
\hline Non-adjacent & 14.8 & 15.1 & 13.1 & $\mathbf{1 4 . 9}$ & 21.0 & 21.8 & 21.3 & $\mathbf{2 1 . 7}$ & 7.9 & 7.4 & 7.1 & $\mathbf{7 . 3}$ \\
\hline Other floor & 10.1 & 9.8 & 9.7 & $\mathbf{1 0 . 0}$ & 15.1 & 16.0 & 15.2 & $\mathbf{1 5 . 3}$ & 4.5 & 4.8 & 4.6 & $\mathbf{4 . 6}$ \\
\hline Outdoor & 14.0 & 13.6 & 12.5 & $\mathbf{1 4 . 0}$ & 25.5 & 25.8 & 26.9 & $\mathbf{2 6 . 2}$ & 9.6 & 9.4 & 9.8 & $\mathbf{9 . 4}$ \\
\hline
\end{tabular}

TABLE II

50 AND 90 PERCENTILES AND STANDARD DEVIATION OF RPL FOR THE DIFFERENT CATEGORIES.

present. These results agree reasonably well with [11] (7.7 dB here versus $6.9 \mathrm{~dB}$ ).

For wall types in the Brazilian Northeast penetration loss values of $0.5-3.5 \mathrm{~dB}$ are obtained (light walls, brick and wood) [21]. For a $35 \mathrm{~cm}$ thick reinforced concrete wall, [19] obtained a nearly constant value of $22 \mathrm{~dB}$ in the frequency range of 1 to $4 \mathrm{GHz}$. For a $12 \mathrm{~cm}$ uniform plater wall, [19] obtains a value of about $4 \mathrm{~dB}$ for frequencies around $1 \mathrm{GHz}$. In the $2.4 \mathrm{GHz}$ ISM band, penetration losses of $1.4-2.9 \mathrm{~dB}$ are obtained for $38.5 \mathrm{~mm}$ thickwood and 15-28 dB for $250 \mathrm{~mm}$ concrete walls [18]. These values of the presented studies are specific for a certain type of walls and may be part of the distribution presented in Fig. 3. Our analysis differs from those in [18], [19], [21] because we investigate the RPL in a statistical way. The values of these studies in Table III are valuable but we are able to provide a statistical distribution of the penetration losses.

\begin{tabular}{|c|c|c|}
\hline Article & Frequency band & Penetration losses \\
\hline COST231 [11] & $1800 \mathrm{MHz}$ & $\begin{array}{l}\text { light walls: } 3.4 \mathrm{~dB} \\
\text { heavy walls: } 6.9 \mathrm{~dB}\end{array}$ \\
\hline Silva et al. [21] & $840 \mathrm{MHz}$ & light walls, brick, wood: $0.5-3.5 \mathrm{~dB}$ \\
\hline Zhang and Hwang [19] & $\begin{array}{c}1-4 \mathrm{GHz} \\
1 \mathrm{GHz}\end{array}$ & $\begin{array}{l}\text { thick reinforced concrete wall: } 22 \mathrm{~dB} \\
12 \mathrm{~cm} \text { uniform plater wall: } 4 \mathrm{~dB}\end{array}$ \\
\hline Mohammed et al. [18] & $2.4 \mathrm{GHz}$ & $\begin{array}{l}38.5 \mathrm{~mm} \text { thickwood: } 1.4-2.9 \mathrm{~dB} \\
250 \mathrm{~mm} \text { concrete walls: } 15-28 \mathrm{~dB}\end{array}$ \\
\hline Article & Frequency band & Floor losses \\
\hline COST231 [11] & $1800 \mathrm{MHz}$ & $18.3 \mathrm{~dB}$ \\
\hline ITU-R P.1238 [20] & $900 \mathrm{MHz}$ & 1 floor: $9 \mathrm{~dB}, 2$ floors: $19 \mathrm{~dB}$ \\
\hline ITU-R P.1238 [20] & $1.8-2.0 \mathrm{GHz}$ & residential environments: $11.2 \mathrm{~dB}$ \\
\hline $\begin{array}{l}\text { Lahteenmaki [24] } \\
\text { Ruiz-Boque [25] }\end{array}$ & $\begin{array}{c}900 \mathrm{MHz} \\
\text { and } 1800 \mathrm{MHz}\end{array}$ & $\begin{array}{l}\text { difference of } 3.5 \mathrm{~dB} \\
\text { compared to [11] }\end{array}$ \\
\hline
\end{tabular}

TABLE III

LITERATURE ABOUT INDOOR PENETRATION LOSSES AND FLOOR LOSSES.

\section{B. Penetration losses as a function of number of floors}

Fig. 4 shows the RPL as a function of the number of floors between gap filler and receiver: the RPL increases generally for an increasing number of floors. Also negative values of RPL are obtained in Fig. 4. These negative values are present for rooms above the room of the gap filler with ceilings consisting of "light" materials (e.g., wood) and for large rooms where the gap filler is installed. Because the electric-field values are averaged over the whole room it is possible that $\mathrm{E}_{\text {same }}$ is lower than $\mathrm{E}_{\text {other }}$ (averaged over the room, see Section III-C), resulting in negative RPL values. A wide range of losses for a certain number of floors is obtained. Therefore we propose here a statistical model for RPL in residential houses:

$$
\mathrm{RPL}=\mathrm{RPL}_{0}[\mathrm{~dB}]+\mathrm{P}[\mathrm{dB}] \cdot \mathrm{FL}+\chi
$$

Where $\mathrm{RPL}_{0}[\mathrm{~dB}]$, and $\mathrm{P}$ (increase in $\mathrm{dB}$ per floor) are the parameters of the model and FL is the floor level $(0,1,2$, or 3). Furthermore, $\chi$ is the statistical variation (around the model) and has a standard deviation $\sigma$.

A fit with two parameters $\left(\mathrm{RPL}_{0}[\mathrm{~dB}]\right.$ and $\left.\mathrm{P}\right)$ is performed. The root-mean-square ( $\mathrm{rms}$ ) deviation of the measurement points was minimized with a linear regression fit. $\mathrm{RPL}_{0}$ equals $4.64 \mathrm{~dB}$ and $\mathrm{P}=4.06 \mathrm{~dB}$ for the fit of Fig. 4 .

The statistical behavior of (2) is investigated by analyzing the deviation in $\mathrm{dB}$ between the model of (2) with estimated parameters $\left(\mathrm{RPL}_{0}\right.$ and $\left.\mathrm{P}\right)$ and the measured RPL samples. The cumulative distribution function or CDF of this deviation (i.e., Prob[Deviation $<$ abscissa]) is constructed and compared to a lognormal CDF with zero median in a least-squares sense. Fig. 5 shows the CDF of the deviations between model and experimental data and the lognormal fit. The standard deviation $\sigma$ of the deviations is $4.22 \mathrm{~dB}$ and the standard deviation of the fitted lognormal distribution is $\sigma_{\text {fit }}=4.34 \mathrm{~dB}$. Both distributions thus agree excellently with a difference of only $0.12 \mathrm{~dB}$ for the standard deviation. To further assess lognormality of the samples, also a statistical goodness-of-fit test was performed. A Kolmogorov-Smirnov (K-S) test was conducted on the samples. All samples passed the K-S test at a significance level $\alpha=0.05$, indicating the lognormal behavior of the model of (2).

Table III also lists literature about floor penetration losses. In [11] (COST231), floor losses at $1800 \mathrm{MHz}$ of $18.3 \mathrm{~dB}$ (noted as $\mathrm{L}_{\mathrm{f}}$ in [11]) are reported while we obtain (using the model of (2)) median values of $8.70,12.75$, and $16.81 \mathrm{~dB}$ for 1,2 , and 3 floors, respectively. These values are lower than those of [11] due to the fact that for the higher floors mostly wooden ceilings were present in the investigated houses and because we investigate a much lower frequency of $514 \mathrm{MHz}$. Moreover the coefficients of [11] are optimized for "dense" environments. From our data it is shown that the room penetration loss is higher for a concrete ceiling than for a wooden ceiling (average RPL values of $6.6 \mathrm{~dB}$ for wood versus $11.0 \mathrm{~dB}$ for concrete ceilings). In [24], [25] a difference of $3.5 \mathrm{~dB}$ in the floor loss compared to the model of [11] is reported. In ITUR P.1238 [20], [23] floor penetration losses of $9 \mathrm{~dB}$ (1 floor) 
and $19 \mathrm{~dB}$ ( 2 floors) for office environments at $900 \mathrm{MHz}$ are reported. The value for 1 floor in [20], [23] corresponds well with our results. The different environment (residential versus office), the different frequency under consideration, and the presence of wooden ceilings for the higher floors in the houses of our study are responsible for differences. For the band 1.8 - $2.0 \mathrm{GHz}$, ITU-R P.1238 obtains $11.2 \mathrm{~dB}$ for the floor penetration loss factor in residential environments [23] (see Table III). No data for residential environments at $900 \mathrm{MHz}$ or lower frequencies is available in [20].

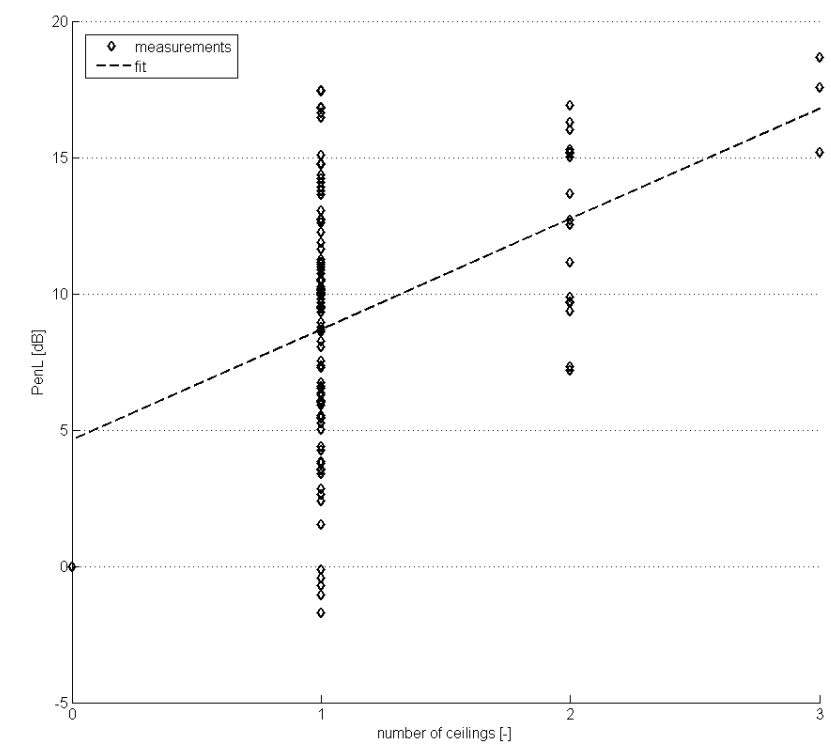

Fig. 4. Measurements and model of RPL for different number of floors of the investigated houses.

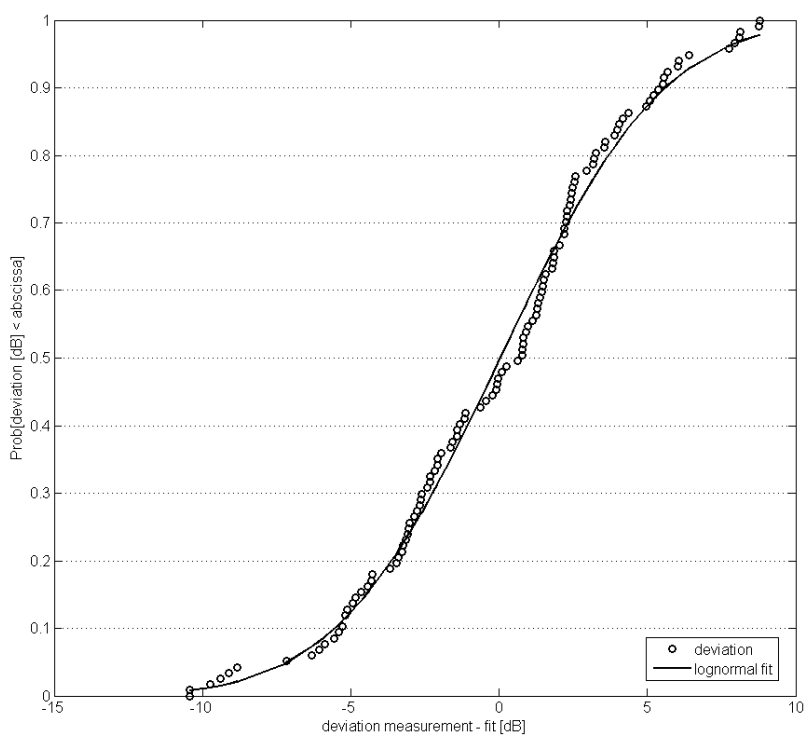

Fig. 5. Cumulative distribution function of deviation of measured RPL and fit for different number of ceilings.

\section{CONCLUSIONS}

In this paper the indoor penetration loss for a DVB-H signal at $514 \mathrm{MHz}$ retransmitted from the HFC-cable network with a gap filler and an indoor antenna is investigated. Measurements of the electric field in 121 rooms of fourteen different houses for three radiated power levels are executed, resulting in a total number of 363 measurements. The rooms of these houses are divided in categories dependent on the position to the transmitter (same room, adjacent room, non-adjacent room, other floor, and outdoor). The room penetration loss is investigated statistically for the different categories. The median room penetration loss for non-adjacent rooms $(\mathrm{RPL}=14.9 \mathrm{~dB})$ is about $7 \mathrm{~dB}$ higher than for adjacent rooms $(\mathrm{RPL}=7.7 \mathrm{~dB})$. The room penetration loss for the category "other floors" is in between the values for adjacent rooms and non-adjacent rooms (median of RPL is $10.0 \mathrm{~dB}$ ). It is shown that the indoor penetration loss values are lognormally distributed.

Finally, penetration losses are modeled as a function of the number of floors in the houses. A fit of the cumulative distribution function and $\mathrm{K}-\mathrm{S}$ tests demonstrated the lognormal behavior of the model. A comparison with existing literature and floor losses is also made.

Broadcasters and operators can use the analysis of this paper to determine the optimal radiated power (and thus cost) of indoor gap fillers to perform link budget calculations for indoor coverage. Future research could consist of the study of the co-existence of the indoor gap filler with an outdoor main DVB-H transmission.

\section{ACKNOWLEDGMENT}

This work was supported by the IBBT-MADUF project, co-funded by the IBBT (Interdisciplinary institute for BroadBand Technology), a research institute founded by the Flemish Government in 2004, and the involved companies and institutions. W. Joseph is a Post-Doctoral Fellow of the FWO-V (Research Foundation-Flanders).

\section{REFERENCES}

[1] ETSI, EN 302304 v1.1.1, "Digital Video Broadcasting (DVB); Transmission System for Handheld Terminals (DVB-H)," Oct. 2004.

[2] ETSI, EN 300744 v1.5.1, "Digital Video Broadcasting (DVB); Framing structure, channel coding and modulation for digital terrestrial television," Nov. 2004.

[3] ETSI, TR 102401 v1.1.1, "Digital Video Broadcasting (DVB); Transmission to Handheld Terminals (DVB-H); Validation Task Force Report," May 2005.

[4] ETSI, TR 102377 v1.1.1, "Digital Video Broadcasting (DVB); DVB-H Implementation Guidelines," Feb. 2005.

[5] G. Faria, j. A. Hendriksson, E. Stare, and P. Talmola, "DVB-H: Digital Broadcast Services to Handheld Devices," Proceedings of the IEEE, vol. 94, no. 1, pp. 194-209, Jan. 2006.

[6] D. Plets, W. Joseph, L. Martens, E. Deventer, and H. Gauderis, "Evaluation and Validation of the Performance of a DVB-H Network," in 2007 IEEE International Symposium on Broadband Multimedia Systems and Broadcasting, Orlando, Florida, USA, Mar. 2007, available on CDROM.

[7] D. Plets, L. Verloock, E. Tanghe, W. Joseph, L. Martens, E. Deventer, and H. Gauderis, "Evaluation of performance characteristics of a DVB$\mathrm{H}$ network for different reception conditions," in 57th Annual IEEE Broadcast Technology Society Symposium, Washington DC, USA, 31 October - 2 November 2007, paper no. 12-07. 
[8] D. Plets, W. Joseph, L. Verloock, E. Tanghe, L. Martens, E. Deventer, and H. Gauderis, "Influence of Reception Condition, MPE-FEC Rate and Modulation Scheme on Performance of DVB-H," IEEE Transactions on Broadcasting (Special Issue on Quality Issues in Multimedia Broadcasting), pp. 590-598, September 2008.

[9] W. Joseph, L. Verloock, D. Plets, E. Tanghe, and L. Martens, "Procedure to Optimize Coverage and Throughput for a DVB-H System Based on Field Trials," IEEE Transactions on Broadcasting, pp. 347-355, September 2008.

[10] European Telecommunications Standards Institute, ETSI EN xxx xxx v0.2.0, "Digital Video Broadcasting (DVB); Technical Specifications for DVB-H Small Gap Fillers," May 2007.

[11] COST 231 Final Report, Digital Mobile Radio Towards Future Generation Systems. Brussels: COST Telecom Secretariat, 1999.

[12] W. Joseph, E. Tanghe, D. Pareit, and L. Martens, "Building penetration measurements for indoor coverage prediction of DVB-H systems," in 2007 IEEE International Symposium on Antennas and Propagation, Honolulu, Hawaii, USA, Jun. 2007, paper No. 1282.

[13] H. X. G. Durgin, T. S. Rappaport, "Measurements and models for radio path loss and penetration loss in and around homes and trees at $5.58 \mathrm{GHz}$," IEEE Trans. Commun., vol. 46, no. 11, pp. 1484-1496, Nov. 1998.

[14] A. Turkmani and A. de Toledo, "Modelling of radio transmissions into, and within buildings at 900, 1800 and $2300 \mathrm{MHz}, "$ IEE Proceedings, vol. 140 , no. 6, pp. 462-470, Dec. 1993.

[15] E. F. T. Martijn and M. H. A. J. Herben, "Characterization of radio wave propagation into buildings at $1800 \mathrm{MHz}$," IEEE Antennas and wireless propagation letters, vol. 2, pp. 122-125, 2003.

[16] D. Plets, W. Joseph, L. Verloock, E. Tanghe, L. Martens, E. Deventer, and H. Gauderis, "Extensive Penetration Loss Measurements and Models for Different Building Types for DVB-H in the UHF Band," IEEE Transactions on Broadcasting, March 2009, accepted.

[17] B. D. Backer, H. Borjeson, D. D. Zutter, and F. Olyslager, "Propagation Mechanisms for UHF Wave Transmission Through Walls and Windows," IEEE Transactions on Vehicular Technology, vol. 52, no. 5, pp. 12971307, Sept 2003.

[18] Y. E. Mohammed, A. Abdallah, and Y. A. Liu, "Characterization of indoor penetration loss at ism band," in Asia-Pasific Conference on Environmental Electromagnetics CEEM'2003, Hangzhou, China, Nov. 2003, pp. 25- 28.

[19] Y. Zhang and Y. Hwang, "Measurements of the characteristics of indoor penetration loss," in Vehicular Technology Conference, 1994 IEEE 44th, vol. 3, Stockholm, Sweden, Jun. 1994, pp. 1741-1744.

[20] ITU-R Recommendation P.1238, "Propagation data and prediction models for the planning of indoor radiocommunication systems and radio local area networks in the frequency range $900 \mathrm{MHz}$ to $100 \mathrm{GHz}, " 1997$.

[21] J. C. e Silva, A. G. Neto, J. N. de Carvalho, and M. S. Alencar, "Determining the average penetration loss: Measurement procedure and results," in Proc. Microwave and Optoelectronics Conference, 1999. SBMO/IEEE MTT-S, APS and LEOS - IMOC apos, vol. 1, 1999, pp. 339-341.

[22] D. Akerberg, "Properties ofa TDMA picocellular office communication system," in Proceedings of IEEE Global Telecommunications Conference globercom '88, vol. 3, Nov 1988, pp. 1343-1349.

[23] S. R. Saunders, Antennas and propagation for wireless communication systems. New York, NY.: John Wiley \& Sons Inc., 1999.

[24] J. Lahteenmaki, "Indoor propagation between floors at $855 \mathrm{MHz}$ and $1.8 \mathrm{GHz}$, , in COST 231 TD(94)37, 1994.

[25] S. Ruiz-Boque, R. Agusti, J. Perez, "Indoor wideband channel characterization (900 and $1800 \mathrm{MHz}$ ) by means of a network analyzer," in COST $231 T D(91) 71,1991$. 